\title{
Kolorektal kanserde endoskopik özellikler tümör patolojisini ve tümör evresini predikte edebilir mi?
}

\author{
Can the endoscopic features of colorectal carcinomas predict tumor pathology and stage?
}

Muhammet Yener AKPINAR ${ }^{1}$, Metin UZMAN¹ ${ }^{1}$, Zeynep GÖKTAŞ³, Gülçin Güler ŞİMŞEK², Evrim KAHRAMANOĞLU AKSOY ${ }^{1}$, Ferdane PIRINÇCI SAPMAZ ${ }^{1}$, Yaşar NAZLIGÜL ${ }^{1}$

Sağlı Bilimleri Üniversitesi, Keçiören Eğitim ve Araștırma Hastanesi, ${ }^{1}$ Gastroenteroloji, ${ }^{2}$ Patoloji, Ankara

Hacettepe Üniversitesi Sağlı Bilimleri Fakültesi Beslenme ve ${ }^{3}$ Diyetetik Bölümü, Ankara

Giriş ve Amaç: Kolorektal kanserli hastalarımızın demografik özelliklerini ve tanı anındaki endoskopik özelliklerinin kolorektal kanserin patolojik özellikleri ile olan ilişkisini incelemeyi hedefledik. Gereç ve Yöntem: Hastanemiz Endoskopi Ünitesinde Ocak 2010-Ekim 2017 tarihleri arasında kolonoskopi esnasinda kolorektal kanser ön tanısı ile biyopsi alınan ve patolojileri kolorektal kanser gelen hastalar çalışmaya dahil edildi. Tümöre bağlı lüminal obstrüksiyon, tümörün makroskopik özellikleri gibi endoskopik özellikler ve kolorektal kanserin patolojik özellikleri retrospektif olarak incelendi. Bulgular: Çalışmamıza 168 hasta dahil edildi. Hastaların en sık bașvuru şikayeti kabızlık olup kolonda kanserin en sık izlendiği yer sigmoid kolondu. Hematokezya sol kolon yerleşimli kanserlerde diğer bölgelerdekine göre anlamlı olarak daha sik izlendi $(p=0.02)$. Cinsiyetler arasında başvuru şekli, kanser lokalizasyonu ve endoskopik obstrüksiyon farklılık göstermedi. Endoskopik obstrüksiyonu olan hastalarda kolorektal kanserin kötü diferansiasyonu anlamlı olarak daha fazlaydı $(p=0.015)$. Sonuç: Endoskopun geçemeyeceği şekilde lüminal obstrüksiyonu olan hastaların yakından izlenmeleri, ameliyatlarının geciktirilmeden yapılması ve ameliyat sonrası daha kısa aralıklarla takibi bu hastaların sağkalımlan üzerine etkili olabilir.

Anahtar kelimeler: Endoskopi, kanser diferansiasyonu, kolorektal kanser
Background and Aims: Our aim was to evaluate the demographic features of our colorectal cancer patients and assess the association between endoscopic and pathologic features in those patients. Materials and Methods: In this study, we retrospectively evaluated the medical records of patients who were diagnosed with colorectal cancer through biopsy taken by colonoscopy in the endoscopy unit of our hospital between January 2010 and October 2017. We analyzed endoscopic features of colorectal cancer such as luminal obstruction, macroscopic appearance, and histological features. Results: We obtained data from 168 patients for this study. The most common symptom was constipation and the most common cancer location was the sigmoid colon. Hematochezia was found to be significantly higher in cancers located in the left colon $(p=0.02)$. Symptoms, cancer location, and endoscopic obstruction were not significantly different between genders. Poor histological differentiation was significantly higher in the endoscopic obstruction group ( $p=0.015$ ). Conclusion: Immediate surgery and close follow-up in patients with endoscopic obstruction can impact their survival.

Key words: Colorectal cancer, cancer differentiation, endoscopy

\section{GİRISS}

Kolorektal kanserler (KRK) tüm dünyada en sı izlenen 3. kanser türü olup kansere bağlı ölümlerin ise 2. en sik nedenidir (1). Tarama programlarının yaygınlaşması ve tedavideki yeniliklere rağmen mortalite oranı bu grup hastalarda halen yüksektir. Endüstriyel toplumlarda, batı tarzı diyetle (az fiber ve yüksek yağ asidi içeren) beslenen ülkelerde sık görülen KRK klinikte kendini farklı şekillerde gösterebilir. Kanama, kabızlık, karın ağrısı, kilo kaybı ve kansızlık hastalarda sık rastlanan başvuru şikayetleridir (2). Hastaların başvuru şikayetleri kanser lokalizasyonuna bağlı olarak da değissir; sağ kolon yerleşimli kanserlerde anemi daha sık izlenirken sol kolon yerleşimli kanserlerde kanama ve/veya dışkı şeklinde değişiklik ve karın ağrısı daha sık görülen şikayetlerdendir. Son yıllarda tarama programlarının yaygınlaşması ve kolonoskopik incelemelerin artışı ile semptoma yol açmamış erken evre KRK'ler daha sık tanı almaktadır (3).

Kolonoskopi KRK tanısında altın standart yöntemdir. Semptomatik hastalarda yapilan kolonoskopide tanı alan KRK'ler sıklıkla ileri evre olarak karşımıza çıkar. Kolonoskopinin KRK'lerde diğer bir görevi ise lümen açıklığını sağlayıcı endoskopik işlemlere olanak sağlamasıdır. Kolonik stentler tanı anında obstrüksiyon bulguları olan hastalarda kullanılabilinir (4). Bu işlevlerin ötesinde KRK'lerin endoskopik özelliklerinin-makroskopik görünüm ve kolonoskopun geçişine izin verip vermeyişi gibi- kanserin patolojik diferransiasyon derecesi ve yaygınlığı gibi özellikleri predikte edip etmeyeceği ile ilgili bilgiler ise sınırlıdır. Biz bu çalışmada KRK'li hastalarımızın tanı anındaki endoskopik özelliklerinin KRK'in patolojik özellikleri ile olan ilişkisini inceledik. Ayrıca endoskopi ünitemizde tanısı konulmuş olan bu KRK'li hastalarımızın demografik verilerini de sunmayı hedefledik.

İletişim: Muhammet Yener AKPINAR SBÜ Keçiören Eğitim ve Araştırma Hastanesi, Gastroenteroloji Bölümü, Keçiören, Ankara, Türkiye • Tel: +90 3123569000 Fax: +90 3123569002 • E-mail: muhammet.yener@gmail.com Geliş Tarihi: 17.12.2017 Kabul Tarihi: 28.09.2018 


\section{GEREÇ ve YÖNTEM}

\section{Çalışma Dizaynı}

Hastanemiz Endoskopi Ünitesinde Ocak 2010-Ekim 2017 tarihleri arasında kolonoskopi esnasında KRK ön tanısı ile biyopsi alınan ve patolojileri KRK gelen hastalar çalışmaya dahil edildi. Bu hastalarm endoskopik özellikleri ile beraber başvuru şikayetleri, KRK'in patolojik özellikleri ve varsa cerrahi öyküleri hastane otomasyon sistemi ve hasta dosyaları incelenerek derlendi.

Kolorektal kanserlerin endoskopik görünümleri ülserovejetan (Resim 1), ülsere (Resim 2), Vejetan (Resim 3), polipoid (Resim 4) ve infiltre olarak siniflandirıldı. Kolorektal kanserin kitle etkisine bağlı gelişen lüminal obstrüksiyon sonucu kolonoskopun lezyon proksimaline geçemeyişi endoskopik obstrüksiyon olarak tanımlandı. Kanser diferansiasyon derecesi iyi diferansiye, orta diferansiye ve kötü diferansiye olarak tanımlandı. Çekum, asendan kolon ve transvers kolon bera-

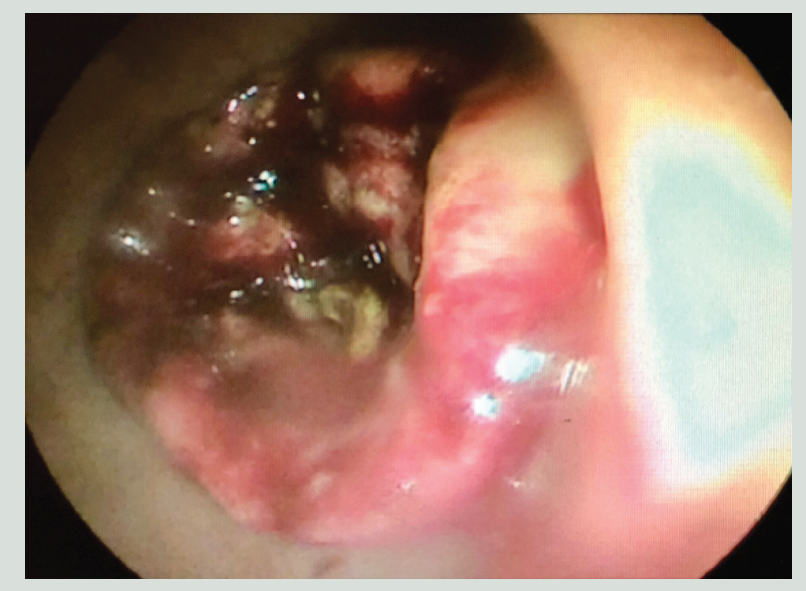

Resim 1. Ülserovejetan kolorektal karsinom.

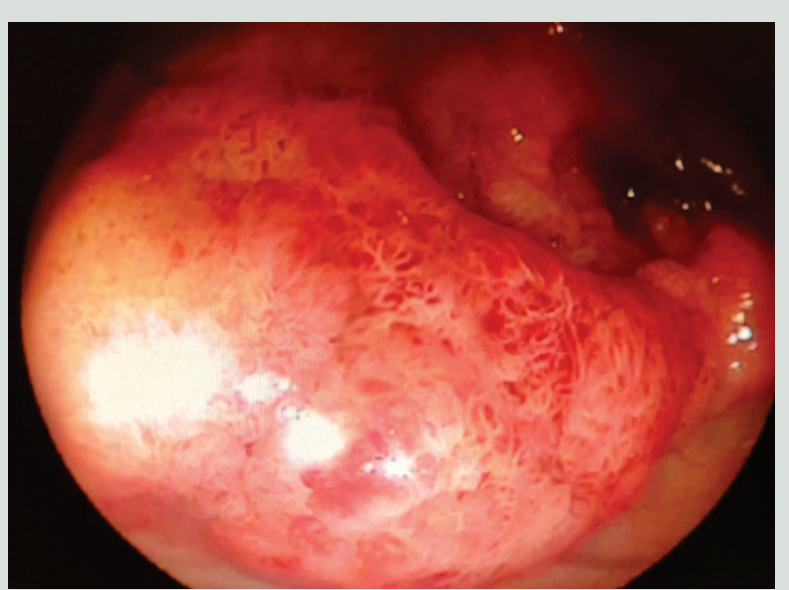

Resim 3. Vejetan kolorektal karsinom. ber sağ kolon, splenik fleksura, inen kolon ve sigmoid kolon sol kolon olarak tanımlandi. Hastanemizde cerrahi olan hastaların bilgileri ameliyat raporları ve ameliyat sonrası patolojik incelemeler derlenerek ayrıca değerlendirildi.

\section{Kolonoskopik İnceleme}

Çalışmaya alınan bütün hastalara kolonoskopi standart çaplı kolonoskopla (EC-450WL-5 Fujinon, Saitema, Japan) ile yapıldı. KRK'den şüphe edilen hastalarda lezyondan çoklu biyopsiler alındi.

\section{İstatistik}

Veriler SPSS IBM 22.0 (New York, ABD) programı kullanılarak analiz edilmiştir. Nominal veriler sayı ve yüzde olarak belirtilmiştir. Sayısal veriler ortalama ve standart sapma olarak belirtilmiştir. Nominal ve ordinal verilerin analizinde Ki-kare testleri kullanılmıştır. İki grup ortalamaları Student t test kullanılarak analiz edilmiştir. P değeri 0.05'in altında istatistiksel olarak anlamlı sayılmıştır.

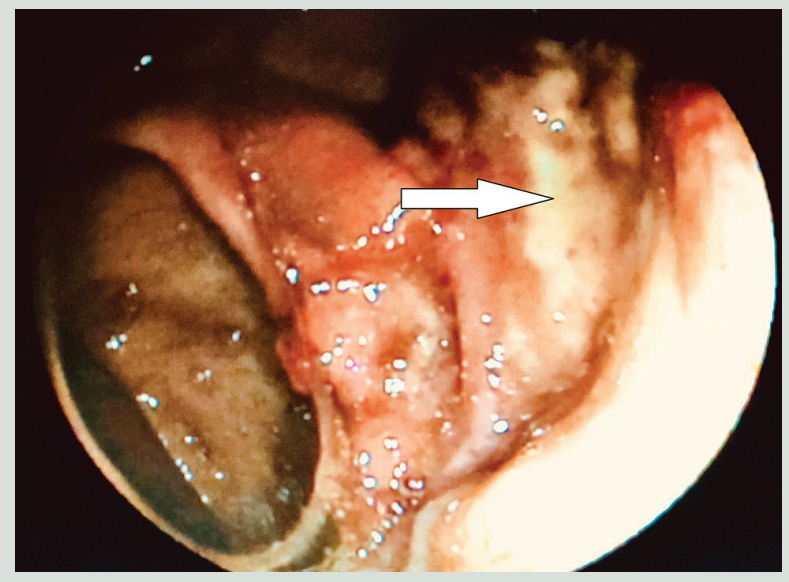

Resim 2. Ülsere (beyaz ok ülserin olduğu alanı göstermekte) kolorektal karsinom.

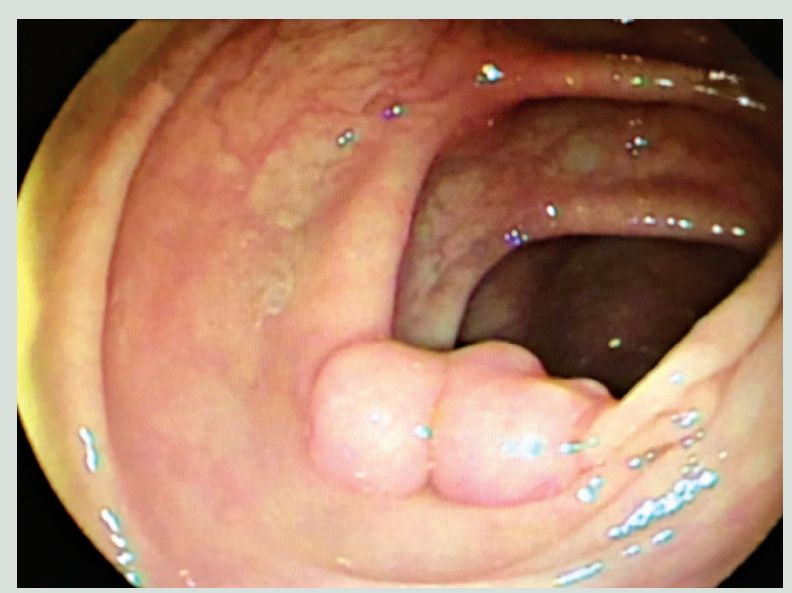

Resim 4. Polipoid görünümde kolorektal karsinom. 


\section{Tablo 1. Hastaların demografik özellikleri}

Değişkenler

Cinsiyet (erkek/kadın)

Yaş ortalaması (erkek/kadın)

Başvuru şikayeti

Kabızlık

Hematokezya

Karın ağrısı

Polip kontrol

Demir eksikliği anemisi

Kronik ishal

Radyolojik görüntülemelerde anormallikler

Gaytada gizli kan pozitifliği

Batında ele gelen kitle

Kanser lokalizasyonu

Çekum

Çıkan kolon

Hepatik fleksura

Transvers kolon

Splenik fleksura

Inen kolon

Sigmoid kolon

Rektosigmoid bileşke

Rektum

Endoskopik obstrüksiyon (Var/yok)

Kanserin makroskopik görünümü

Ülserovejetan

Ülsere

Vejetan

Polipoid

Infiltre

Polip tespit edilen hastalar

Tek polip

Çoklu polip

Kanser diferansiasyon derecesi

Değerlendirilemeyen hastalar

Değerlendirilebilen hastalar

tyi diferansiye

Orta diferansiye

Kötü diferansiye

Cerrahi sonuçlarına ulaşılan hastalar

Serozal tutulum pozitif olan hastalar (T4)

Lenf nodu tutulumu pozitif olan hastalar (N1)

Taşlı yüzük hücreli komponent pozitif olan hastalar

BAD: Barsak alışkanlığında değişiklik.

\section{Sayı}

92/76

$64.9 \pm 11.48 / 65.1 \pm 13.11$

$57(\% 33.9)$

$35(\% 20.8)$

18 (\% 10)

$3(\% 1.7)$

$29(\% 17.2)$

$6(\% 3.5)$

16 (\%9.5)

3 (\% 1.7)

1 (\%0.5)

$9(\% 5.3)$

19 (\%11.3)

6 (\%3.5)

$8(\% 4.7)$

7 (\%4.1)

16 (\%9.5)

28 (\%16.6)

5 (\%2.9)

70 (\%41.6)

$76 / 90$

127 (\%75.5)

24

9

7

1

59 (\%35.1)

33

26

93

75

41 (\%54.6)

20 (\%26.2)

14 (\%19.2)

32 (\%19)

27 (\%84.3)

11 (\%34.3)

5 (\%15.6) 


\section{Etik Onay}

Çalışmamız Sağlık Uygulama Araştırma Merkezi Tıpta Uzmanlık Eğitimi Kurulu Onayı alınarak yapılmıştır.

\section{BULGULAR}

Çalışmamıza toplam 168 hasta dahil edildi. Bu hastalarımızın 76'sı kadın, 92'si erkek olup yaş ortalaması kadınlar için $65.1 \pm 13.11$, erkekler için $64.9 \pm 11.48$ olarak bulundu. Hastaların başvuru şikayetleri çok farklı olup sırasıyla kabızlık en sık izlenen başvuru şikayetiydi (57 hasta). Bunu sırasıyla hematokezya (35 hasta), demir eksikliği anemisi (DEA) (29 hasta), karın ağrısı (18 hasta), radyolojik görüntüleme yöntemlerindeki anormal görünümlerin tetkik edilmesi (16 hasta), kronik ishal (6 hasta), gaytada gizli kan pozitifliği (3 hasta), polip kontrolü (3 hasta) ve batında ele gelen kitle (1 hasta) takip etti. Radyolojik görüntüleme yöntemlerinde izlenen anormal sonuçların izlendiği hastaları ise bilgisayarlı tomografi (BT)'de kolon duvar kalınlık artışı, farklı nedenlerle çekilen ozitron emisyon tomografisi-bilgisayarlı tomografi (PET-BT)'de kolonda patolojik tutulum olması ve karaciğerde metastatik lezyonlar tespit edilen hastalar oluşturmaktaydı.

Kolorektal kanserlerin dağılımları incelendiğindeyse 70 hastanın kanseri rektumda lokalizeydi. Kolonik yerleşim (98 hasta) olarak en sik etkilenen bölge sigmoid kolon (28 hasta) olup bunu sirasıyla çıkan kolon (19 hasta), inen kolon (18 hasta), çekum (9 hasta), transvers kolon (8 hasta), splenik fleksura ( 7 hasta), hepatik fleksura (6 hasta) ve rektosigmoid bileşke (5 hasta) takip ediyordu. Kolonoskop 90 hastada (\%53.5) KRK'in yol açtığı lüminal obstrüksiyondan proksimale doğru geçebilmişti. Makroskopik olarak en sık görülen KRK şekli ülserovejetan tipti (127 hasta, \% 75.5). Histopatolojik olarak kanser diferansiasyon derecesi 75 hastada değerlendirilebildi; iyi diferansiye KRK 41 hastada (\%54.6), orta diferansiasyon 20 hastada (\%26.2), kötü diferansiasyon ise 14 hastada (\%19.2) tespit edildi. Endoskopi ünitemizde KRK tanısı konulan hastaların 32 tanesi hastanemizde opere olmuştu. Ameliyat sonrası patolojik değerlendirmede ise 5 hastada taşlı yüzük hücreli komponent izlendi (Tablo 1). Cinsiyetlere göre Tablo l'de verilen değişkenler açısından karşılaştırıldığında gruplar arasında anlamlı bir farklılık bulunmadi.

Hastaların başvuru şikayetleri ve kanserin lokalizasyonu arasındaki ilişki incelendiğindeyse hematokezya ile başvuran hastalarda KRK 1 hasta dişında tamamen sol kolon ve rektum yerleşimli olup istatistiksel anlamlı farklılık gösterdi ( $p<0,001)$. Buna benzer şekilde tomografide duvar kalınlık artışı, özellikle sağ kolon yerleşimli kolon kanserlerinde daha belirgin olup istatistiksel olarak anlamliyd $(p=0,011)$. Demir eksikliği anemisi sağ ve sol kolon yerleşimli kanserlerde rektal kanserlere göre daha sık görülen bir başvuru şikayetiydi $(\mathrm{p}=0,004)$. Kronik ishal ise rektal yerleşimli kanserlerde diğer lokalizasyonlara göre daha sıktı $(\mathrm{p}=0,043)$. Diğer başvuru şikayetleri ile KRK yerleşimi arasında ise istatistiksel anlamlı bir fark bulunmadı. Bununla beraber kabızlık ve kronik ishalle başvuran hastalarda KRK yerleşimi çoğunlukla sol kolon iken demir eksikliği anemisi ve BT'de duvar kalınlık artışı ile başvuran hastalarda ise KRK dağılımı daha homojendi (Tablo 2).

Kolorektal kanserlerin makroskopik görüntüsü ile kanserin patolojik diferansiasyon derecesi de karşılaştırıldı. Önceden belirtildiği gibi en sık görülen makroskopik görünüm ülserovejetan tip, en az görüleni ise infiltratif tipti. Her ne kadar ülserovejetan tipteki hastaların çoğu iyi diferansiasyon gösterseler de kanser diferansiasyon derecesi ile arasında bir farklılık bulunmadı. Buna benzer olarak diğer makroskopik görünüm şekilleri ile de kanserin diferansiasyon derecesi arasinda istatisksel bir farklılığa rastlanmadı ( $>$ >0.05) (Tablo 3).

Tablo 2. Başvuru şikayetine göre kaner lokalizasyonu dağılımı (n, \%).

\begin{tabular}{|c|c|c|c|c|c|c|c|c|c|}
\hline & \multicolumn{2}{|c|}{ Sağ Kolon } & \multicolumn{2}{|c|}{ Sol Kolon } & \multicolumn{2}{|c|}{ Rektum } & \multicolumn{2}{|c|}{ Toplam } & \multirow[t]{2}{*}{$\mathbf{p}$} \\
\hline & $\mathbf{N}$ & $\%$ & $\mathbf{N}$ & $\%$ & $\mathbf{N}$ & $\%$ & $\mathbf{N}$ & $\%$ & \\
\hline Kabızlık & 17 & 29.8 & 21 & 36.9 & 19 & 33.3 & 57 & 100.0 & $\mathrm{p}>0.05$ \\
\hline Hematokezya & 1 & 2.8 & 10 & 28.6 & 24 & 68.6 & 35 & 100.0 & $\mathrm{p}<0.001$ \\
\hline Karın ağrısı & 5 & 27.8 & 8 & 44.4 & 5 & 27.8 & 18 & 100.0 & $\mathrm{p}>0.05$ \\
\hline Polip kontrol & 1 & 33.3 & 1 & 33.3 & 1 & 33.3 & 3 & 100.0 & $\mathrm{p}>0.05$ \\
\hline Demir eksikliği anemisi & 13 & 44.7 & 12 & 41.3 & 4 & 12.8 & 29 & 100.0 & $\mathrm{p}=0.004$ \\
\hline Kronik ishal & \multicolumn{2}{|c|}{---} & 1 & 16.7 & 5 & 83.3 & 6 & 100.0 & $\mathrm{p}=0.043$ \\
\hline CT duvar kalınlığı artış & 7 & 70.0 & 2 & 20.0 & 1 & 10.0 & 10 & 100.0 & $\mathrm{p}=0.011$ \\
\hline Gaytada gizli kan pozitifliği & \multicolumn{2}{|c|}{--- } & 1 & 33.3 & 2 & 66.7 & 3 & 100.0 & $\mathrm{p}>0.05$ \\
\hline Karaciğer metastazı primer? & 2 & 50.0 & 1 & 25.0 & 1 & 25.0 & 4 & 100.0 & $\mathrm{p}>0.05$ \\
\hline PET-CT tutulum & 1 & 50.0 & \multicolumn{2}{|c|}{--- } & 1 & 50.0 & 2 & 100.0 & $\mathrm{p}>0.05$ \\
\hline Batında ele gelen kitle & \multicolumn{2}{|c|}{--- } & \multicolumn{2}{|c|}{---} & 1 & 100.0 & 1 & 100.0 & $\mathrm{p}>0.05$ \\
\hline
\end{tabular}


Tablo 3. Kolorektal kanserin makroskopik görünümüne göre kanser diferansiasyon derecesinin değerlendirilmesi

\begin{tabular}{|c|c|c|c|c|c|c|c|c|c|c|c|}
\hline \multirow{3}{*}{ Makroskopik görün } & \multicolumn{2}{|c|}{ Belli Değil } & \multicolumn{2}{|c|}{ Iyi } & \multicolumn{2}{|c|}{ Orta } & \multicolumn{2}{|c|}{ Yüksek } & \multicolumn{2}{|c|}{ Toplam } & \multirow[t]{2}{*}{$\mathbf{p}$} \\
\hline & & & & & & & & & & & \\
\hline & $\mathbf{N}$ & $\%$ & $\mathbf{N}$ & $\%$ & $\mathbf{N}$ & $\%$ & $\mathbf{N}$ & $\%$ & $\mathbf{N}$ & $\%$ & \\
\hline Ülserovejetan & 48 & 44.1 & 34 & 31.2 & 14 & 12.8 & 13 & 11.9 & 109 & 100.0 & $\mathrm{p}>0.05$ \\
\hline Ülser & 10 & 52.6 & 4 & 21.1 & 4 & 21.1 & 1 & 5.3 & 19 & 100.0 & $\mathrm{p}>0.05$ \\
\hline Vejetan & 5 & 62.5 & 2 & 25.0 & 1 & 12.5 & --- & & 8 & 100.0 & $\mathrm{p}>0.05$ \\
\hline Polipoid & 2 & 50.0 & 1 & 25.0 & 1 & 25.0 & --- & & 4 & 100.0 & $\mathrm{p}>0.05$ \\
\hline Infiltre & 1 & 100.0 & --- & & --- & & --- & & 1 & 100.0 & $\mathrm{p}>0.05$ \\
\hline
\end{tabular}

Kolonoskopun kansere bağlı oluşan lüminal darlıktan geçip geçmemesine göre hastalar iki gruba ayrıldılar. Endoskopik obstrüksiyonu olmayan 90 hasta ile endoskopik obstrüksiyonu olan 78 hasta arasında yaş, cinsiyet, demografik özellikler, kanserin maksimum uzunluğu, kanser lokalizasyonu, kanserin diferansiasyon derecesi, serozal tutulum sıklığı ve perikolonik lenf nodu tutulumu karşılaştırıldı (Tablo 4). Gruplar arasında yaş, cinsiyet, başvuru şikayeti arasında fark yoktu. Splenik fleksura, inen kolon ve sigmoid kolonda yerleşik kanserlerde kolonoskopun geçiş oranı anlamlı olarak daha düşüktü (sırasıyla $\mathrm{p}=0.027, \mathrm{p}=0.001$ ve $\mathrm{p}=0.004$ ). Rektum yerleşimli kanserlerde ise kolonoskopun geçme oranı anlamlı olarak daha fazlaydı ( $\mathrm{p}<0.001)$. Ülserovejetan görünüme sahip kanserlerde endoskopik darlık anlamlı düzeyde daha fazlaydı ( $\mathrm{p}<0.001$ ). Kanser diferansiasyon derecesi incelendiğinde ise kötü diferansiye kanserler endoskopik obstrüksiyonu olan grupta anlamlı olarak daha sık görüldü $(\mathrm{p}=0.015)$. Serozal tutulum (T4) ise endoskopik obstrüksiyonu olmayan grupta anlamlı olarak daha sık izlendi $(\mathrm{p}=0.006)$.

\section{TARTIŞMA}

Kolorektal kanserler; günümüzde, tarama, tanı ve tedavisindeki ilerlemelere rağmen kansere bağlı ölümlerin başta gelene nedenlerindendir (5). Kolorektal kanserler ileri yaş hastalığı olup eğer altta yatan familyal adenomatöz polipozis gibi herediter bir hastalık, inflamatuvar barsak hastalıkları, ailevi yatkınlık gibi nedenler yoksa 5. dekat ve sonrasinda ortaya çıkar (6). Bizim çalışmamızda da hastaların yaş ortalamaları literatürle uyumlu olarak 60 yaş ve üzerinde daha sıktı. Rektum hariç tutulursa KRK'ler en sık sol kolonu tutmaktadırlar; bizim çalışmamızda da literatürle uyumlu olarak kolon kanserleri sol kolonda daha sik izlendi. Kolorektal kanseri olan hastalarda farklı başvuru şikayetleri izlenebilir. Bu şikayetler kanserin lokalizasyonu ile de ilişkilidir. Çalışmamızda hematokezya literatürle uyumlu olarak sol kolon kanserlerinde anlamlı bir şekilde daha sık izlendi (7). Demir eksikliği anemisi, kolorektal kanserlerin iyi bilinen bir belirtisi olup klasik literatür bilgisi sağ kolon yerleşimli kanserlerde daha sık görüldüğüdür. Wilson ve arkadaşlarının yaptıkları yakın tarihli çalışmada da DEA sağ kolon kanserlerinde daha sıktır; aynı zamanda DEA ileri TNM evresi ve ileri yaşla da ilişkili bulunmuştur (8). Bizim çalışmamızda DEA sağ ve sol kolon yerleşimli KRK'de benzer sıklıkta izlenirken rektum kanserlerine göre her iki grupta da daha sık izlenildi. Bunların ötesinde KRK tanısı asemptomatik hastalarda da konulabilir. Günümüzde farklı nedenlerle çekilen görüntüleme yöntemlerinde kolorektal bölgedeki anormal bulgular (duvar kalınlık artışı, PET-BT'de tutulum gibi) bazı hastalarda KRK habercisi olabilir. Bizim çalışmamızda da 16 hastada (\%9.5) KRK tanısı görüntüleme yöntemlerindeki anormal bulguların araştırılması esnasında konuldu. Pratikte kolorektal bölge duvar kalınlık artışı ilk olarak akla KRK'i getirse de inflamatuvar barsak hastalıkları ve divertikülit gibi bir çok neden de kolonda duvar kalınlık artışına yol açabilir $(9,10)$. Çalışmamızda sağ kolon yerleşimli KRK'de kolon duvar kalınlık artışına anlamlı olarak daha sik rastlandı.

Kolorektal kanserin endoskopik özelliklerinin hastalığın histopatolojik özellikleri ile ilişkisini inceleyen çalışamalar sınırlıdır. Biz çalışmamızda kötü diferansiasyon gösteren KRK’ler, endoskopik darlığın olduğu grupta, kolonoskopun lezyon proksimaline geçtiği hastalara göre anlamlı olarak daha fazla izlendi ( $\mathrm{p}=0.015$ ). Kolorektal kanserlerde obstrüksiyonla başvuran hastaların surveyinin daha düşük olduğu çalışmalarda gösterilmiştir $(11,12)$. Virote ve arkadaşları yaptıkları çalışmada endoskopik obstrüksiyona sahip hastaların acil cerrahi ihtiyacının daha fazla olduklarını göstermişlerdir (13). Aynı çalışmada tümör diferansiasyonu endoskopik obstrüksiyonu olan hastalarla obstrüksiyonu olmayan hastalar arasında farklılık göstermemiştir. Bununla beraber endoskopik obstrüksiyonu olan hastalarda prognozun kötü olmasının nedeni KRK'in kötü diferansiasyon göstermesinden ve/veya daha ileri evre olmasından kaynaklanıyor olabilir. Çalışmamızda endoskopik obstrüksiyonu olmayan hastalarda serozal tutulum (T4) endoskopik obstrüksiyonu olan hastalara göre anlamlı olarak daha fazlaydı ( $\mathrm{p}=0.006)$. Ballian ve arkadaşlarının yaptıkları çalışma da kolonoskopun geçemediği KRK'lerin daha sık olarak evre 4 hastalığa sahip olduklarını göstermiştir (14). 
Tablo 4. Değişkenlerin endoskopik obstrüksiyonu olan ve olmayan hastalar arasında karşılaștırılması

\begin{tabular}{|c|c|c|c|}
\hline Yaş (yll) (Ort $\pm S S)$ & $\begin{array}{c}\text { Endoskopik } \\
\text { Obstrüksiyon Yok } \\
(\mathbf{n}=\mathbf{9 0}) \\
65.4 \pm 12.21\end{array}$ & $\begin{array}{c}\text { Endoskopik } \\
\text { Obstrüksiyon Var } \\
(\mathbf{n}=\mathbf{7 8}) \\
64.5 \pm 12.27\end{array}$ & $\mathrm{p}>0.05$ \\
\hline Cinsiyet (E) (n, \%) & $47, \% 51.1$ & $45, \% 48.9$ & $\mathrm{p}>0.05$ \\
\hline \multicolumn{4}{|l|}{ Başvuru şikayeti } \\
\hline Kabızlık (n, \%) & $34, \% 59.6$ & $23, \% 40.4$ & $\mathrm{p}>0.05$ \\
\hline Hematokezya (n, \%) & $23, \% 65.7$ & $12, \% 34.3$ & $\mathrm{p}>0.05$ \\
\hline Karın ağrısı $(n, \%)$ & $7, \% 30.0$ & $11, \% 70.0$ & $\mathrm{p}>0.05$ \\
\hline Polip kontrol (n, \%) & $1, \% 33.3$ & $2, \% 66.7$ & $\mathrm{p}>0.05$ \\
\hline Demir ekiskliği anemisi (n, \%) & $15, \% 51.7$ & $14, \% 48.3$ & $\mathrm{p}>0.05$ \\
\hline Kronik ishal (n, \%) & $3, \% 50.0$ & $3, \% 50.0$ & $\mathrm{p}>0.05$ \\
\hline CT duvar kalınlığında artış (n, \%) & $3, \% 30.0$ & $7, \% 70.0$ & $\mathrm{p}>0.05$ \\
\hline Gaytada gizli kan pozitifliği(n, \%) & $2, \% 66.7$ & $1, \% 33.3$ & $\mathrm{p}>0.05$ \\
\hline Karaciğer metastazı primer? (n, \%) & $1, \% 25.0$ & $3, \% 75.0$ & $\mathrm{p}>0.05$ \\
\hline PET-CT tutulum (n, \%) & $1, \% 50.0$ & $1, \% 50.0$ & $\mathrm{p}>0.05$ \\
\hline Batında ele gelen kitle (n, \%) & $1, \% 100.0$ & --- & $\mathrm{p}>0.05$ \\
\hline Polip var (n, \%) & $39, \% 66.1$ & $20, \% 33.9$ & $\mathrm{p}=0.017$ \\
\hline Lezyon çapı (mm) & $41.5 \pm 22.45$ & $54.7 \pm 22.98$ & $\mathrm{p}>0.05$ \\
\hline Polip sayısı (tek) (n, \%) & $20, \% 60.6$ & $13, \% 39.4$ & $\mathrm{p}>0.05$ \\
\hline Polip sayısı (çoklu) (n, \%) & $19, \% 73.1$ & $7, \% 26.9$ & $\mathrm{p}>0.05$ \\
\hline \multicolumn{4}{|l|}{ Kanser lokalizasyonu } \\
\hline Çekum (n, \%) & $6, \% 66.7$ & $3, \% 33.3$ & $\mathrm{p}>0.05$ \\
\hline Çıkan kolon (n, \%) & $11, \% 57.9$ & $8, \% 42.1$ & $\mathrm{p}>0.05$ \\
\hline Hepatik fleksura (n, \%) & $3, \% 50.0$ & $3, \% 50.0$ & $\mathrm{p}>0.05$ \\
\hline Transvers kolon (n, \%) & $3, \% 37.5$ & $5, \% 62.5$ & $\mathrm{p}>0.05$ \\
\hline Splenik fleksura (n, \%) & $1, \% 14.3$ & $6, \% 85.7$ & $\mathrm{p}=0.027$ \\
\hline Inen kolon (n, \%) & $2, \% 12.5$ & $14, \% 87.5$ & $\mathrm{p}=0.001$ \\
\hline Sigmoid kolon (n, \%) & $8, \% 28.6$ & $20, \% 71.4$ & $\mathrm{p}=0.004$ \\
\hline Rektosigmoid bileşke (n, \%) & $3, \% 60.0$ & $2, \% 40.0$ & $\mathrm{p}>0.05$ \\
\hline Rektum (n, \%) & $53, \% 75.7$ & $17, \% 24.3$ & $\mathrm{p}<0.001$ \\
\hline \multicolumn{4}{|l|}{ Makroskopik görünüm } \\
\hline Ülserovejetan (n, \%) & $54, \% 42.5$ & $73, \% 57.5$ & $\mathrm{p}<0.001$ \\
\hline Ülsere (n, \%) & $23, \% 95.8$ & $1, \% 4.2$ & $\mathrm{p}<0.001$ \\
\hline Vejetan (n, \%) & $5, \% 62.5$ & $3, \% 37.5$ & $\mathrm{p}>0.05$ \\
\hline Polipoid (n, \%) & $6, \% 85.7$ & $1, \% 14.3$ & $\mathrm{p}>0.05$ \\
\hline Infiltre (n, \%) & $1, \% 100.0$ & --- & $\mathrm{p}>0.05$ \\
\hline \multicolumn{4}{|l|}{ Kanser diferansiasyon derecesi } \\
\hline Iyi $(n, \%)$ & $19, \% 46.3$ & $22, \% 53.7$ & $\mathrm{p}>0.05$ \\
\hline Orta (n, \%) & $12, \% 60.0$ & $8, \% 40.0$ & $\mathrm{p}>0.05$ \\
\hline Yüksek (n, \%) & $3, \% 21.4$ & $11, \% 78.6$ & $\mathrm{p}=0.015$ \\
\hline Cerrahi var (n, \%) & $1, \% 50.0$ & $1, \% 50.0$ & $\mathrm{p}>0.05$ \\
\hline Taşlı yüzük hücreli komponent (n, \%) & $1, \% 20.0$ & $4, \% 80.0$ & $\mathrm{p}>0.05$ \\
\hline Serozal tutulum var (n, \%) & $8, \% 29.6$ & $19, \% 70.4$ & $\mathrm{p}=0.006$ \\
\hline Perikolonik LAP var (n, \%) & $2, \% 18.2$ & $9, \% 81.8$ & $\mathrm{p}>0.05$ \\
\hline
\end{tabular}


Kanserin makroskopik görüntüsü ile serozal tutulum ve tümör diferansiasyonu arasında bir ilişki bulunmamıştır. Ekspansif tip KRK'lerin en sık görülen makroskopik görünüm şekli olup lüminal obstrüksiyonla daha çok beraberlik gösterir. Dai ve arkadaşlarının yaptıkları çalışmada ülseratif ve infiltratif tip survey için bağımsız prediktörler olarak bulunmuştur (15). Bizim çalışmamızda ise KRK'in endoskopik görünütüsü ile tümör evresi ve patolojik diferansiasyon derecesi arasında bir ilişki bulunamamıştır.

Çalışmamızın bazı kısıtlayıcı tarafları vardır. Retrospektif dizayn çalışmamızın en önemli kısıtlayıcı özelliğidir. Buna bağlı olarak çalışmaya alınan bazı hastaların patolojik bilgilerine ulaşılamamıştır. Başvurusu esnasında hastaların sigara ve alkol kullanımı, diyet özellikleri ve ailede KRK varlığı gibi

\section{KAYNAKLAR}

1. Araujo SE, Alves PR, Habr-Gama A. Role of colonoscopy in colorectal cancer. Rev Hosp Clin Fac Med Sau Paulo 2011;56:25-35.

2. Patil PS, Saklani A, Gambhire P, et al. Colorectal cancer in India: An audit from a tertiary center in a low prevalence area. Indian J Surg Oncol 2017;8:484-90

3. Huang JJ, Huang JL. Challenges to the adoption of risk algorithms for colorectal cancer screening programmes: perspectives for future research. Hong Kong Med J 2017;23:661-3

4. Gallo G, Sammarco G, Chiriatti AP, et al. The role of self-expandable metallic stents as "bridge to surgery" for the treatment of acute malignant colorectal obstruction. Our experience. Ann Ital Chir 2017;6:418-24.

5. Weng W, Feng J, Qin H, Ma Y. Molecular therapy of colorectal cancer: progress and future directions. Int J Cancer 2014;136:493-502.

6. Özkan ÖF, Kaya Ü, Güner A, et al. Bir eğitim ve araştırma hastanesinde kolorektal kanser hastalarının demografik dağılımı ve hastalık özellikleri. Pam Tip Derg 2012;5:132-5.

7. Baer C, Menon R, Bastawrous S, Bastawrous A. Emergency presentations of colorectal cancer. Surg Clin North Am 2017;97:529-45.

8. Wilson MJ, Dekker JWT, Harlaar JJ, et al. The role of preoperative iron deficiency in colorectal cancer patients: prevalence and treatment. Int J Colorectal Dis 2017;32:1617-24. önemli demografik verilere de çalışmanın retrospektif özelliğinden dolayı ulaşılamamıştır. Hastalarımızın yaşam süreleri, cerrahi sonrası kısa ve uzun dönem takip sonuçları ve varsa aldıkları medikal tedaviye yanıtları konusunda da bilgi sahibi olunamamıştır.

Sonuç olarak endoskopik inceleme KRK tanısında altın standart yöntem olup bazı endoskopik özellikler klinisyen için hastalık prognozu hakkında yol gösterici olabilir. Endoskopik obstrüksiyonu olan hastaların yakın izlenmeleri, ameliyatlarının geciktirilmeden yapılması ve ameliyat sonrası daha kısa aralıklarla takibi bu hastaların sağkalımları üzerine etkili olabilir. Bu konuyla ilgili prospektif ve hasta sayısı daha fazla olan çalışmalara ihtiyaç vardır.

9. Ince AT, Baysal B, Kayar Y, et al. Comparison of tomographic and colonoscopic diagnoses in the presence of colonic wall thickening. Int J Clin Exp Med 2014;7:4413-9.

10. Dickerson EC, Chong ST, Ellis JH, et al. Recurrence of colonic diverticulitis: identifying predictive CT findings-retrospective cohort study. Radiology 2017;285:850-8.

11. Mohd Suan MA, Tan WL, Soelar SA, et al. Intestinal obstruction: predictor of poor prognosis in colorectal carcinoma? Epidemiol Health 2015;37:e2015017.

12. Rasool A, Bari S, Rashid S, et al. Outcome of patients with acute intestinal obstruction due to colorectal carcinoma. Internet J Surg 2008;20:1.

13. Chalieopanyarwong V, Boonpipattanapong T, Prechawittayakul P, Sangkhathat $\mathrm{S}$. Endoscopic obstruction is associated with higher risk of acute events requiring emergency operation in colorectal cancer patients. World J Emerg Surg 2013;8:34

14. Ballian N, Mahvi DM, Kennedy GD. Colonoscopic findings and tumor site do not predict bowel obstruction during medical treatment of stage IV colorectal cancer. Oncologist 2009;14:580-5.

15. Dai W, Li Y, Meng X, et al. Does tumor size have its prognostic role in colorectal cancer? Re-evaluating its value incolorectal adenocarcinoma with different macroscopic growth pattern. Int J Surg 2017;45:105-12. 